\title{
Determining the technological mode of foaming of blocked heat-insulating material based on liquid glass in microwave equipment
}

\author{
T.Rymar \\ V. Dahl East Ukrainian National University, 59a Radianskyi Prosp., \\ 93400 Severodonetsk, Ukraine
}

Received October 24, 2017

The foaming process of liquid glass composition during production of blocked heat-insulating material based on liquid glass in the microwave equipment has been researched. The optimum conditions for obtaining the heat-insulating materials using microwave irradiation have been determined. It has been shown that usage of microwave irradiation allows performing the bulk heating of all layers of the liquid glass composition, obtaining the qualitative material and reducing the energy consumption during manufacturing of these products.

Keywords: blocked heat-insulating material, liquid glass, foaming, microwave irradiation, technological parameters.

\begin{abstract}
Исследован процесс поризации жидкостекольной композиции при изготовлении блочного теплоизоляционного материала на основе жидкого стекла в СВЧ-установке. Определены оптимальные условия получения теплоизоляционных материалов с использованием СВЧ-излучения. Показано, что использование СВЧ-излучения позволяет осуществить объемный прогрев всех слоев жидкостекольной композиции, получить качественный материал и сократить энергорасходы при изготовлении данных изделий.
\end{abstract}

Визначення технологічного режиму спучування блокового теплоізоляційного матеріалу на основі рідкого скла у НВЧ-установці. Т.Е.Римар.

Досліджено процес поризації рідкоскляної композиції при виготовленні блокового теплоізоляційного матеріалу на основі рідкого скла у НВЧ-установці. Визначено оптимальні умови отримання теплоізоляційних матеріалів з використанням НВЧ-випромінювання. Показано, що використання НВЧ-випромінювання дозволяє здійснити об'ємний прогрів всіх шарів рідкоскляної композиції, отримати якісний матеріал та скоротити енерговитрати при виготовленні даних виробів.

\section{Introduction}

From the beginning of the 21st century, the mankind faces a number of serious problems, related to energy efficiency one way or another, in particular, due to the rise in price of natural gas. Large industrial enterprises, factories, and various social objects have found themselves in such a difficult situation.

One of the methods of solving this problem is insulation of various buildings, houses, accommodation facilities, various types of constructions by insulating materials. Usage of the insulating materials allows to reduce thickness and mass of walls and other enclosing structures, to decrease heat loss of heated buildings and as a result to reduce fuel consumption [1].

In this case, the most optimal in terms of the polymer industry is foamed materials. Work in this direction is carried out quite intensively. Currently, there are developed foamed materials based on almost all poly- 
mers produced by industry. However, operating temperatures range of such materials does not exceed of $100-150^{\circ} \mathrm{C}$. In this regard, it is essential to develop a technology for obtaining the foamed materials with high thermal resistance. Insulating materials based on inorganic polymer-liquid glass-occupy a special place among the traditional methods of heat insulation due to its almost absolute incombustibility and high biostability [2].

This paper proposes to produce blocked heat-insulating materials based on the liquid glass granules and the binder on the basis of liquid glass, and target additives. They are produced by thermal foaming. Currently, large-scale production of the blocked heat-insulating materials based on liquid glass is not established. It is caused by difficulties of heating the inner layers of the liquid glass composition, which makes it impossible to obtain the qualitative materials with homogeneous finely porous structure and high strength properties [3]. Therefore, the heat-insulating materials based on liquid glass are produced mainly in the form of granules [4-7]. Usage of the microwave irradiation equipment allows the performing bulk heating of all layers of the liquid glass composition and obtaining the qualitative material. In addition, usage of the microwave equipment allows significantly reduce energy and time consumption during manufacturing of these products.

The purpose of the current research is to determine the optimal conditions for obtaining the blocked heat-insulating materials with usage of microwave irradiation, as well as to analyze the temperature change of the sample layer during the process, which will allow determining the process duration and effectiveness of influence of one or other power of microwave irradiation on the sample being foamed.

\section{Experimental}

The microwave equipment for foaming uses the electromagnetic field to force water molecules contained in liquid glass to absorb microwave energy, resulting in rapid increase in the vapour temperature inside the material. Since the rate of inner vapour formation is higher than the rate of vapour migration, and then there appears a pressure gradient in the material that causes significant structural changes in the liquid glass composition. This leads to the foaming.

In order to determine optimum conditions for the liquid glass composition foaming of, the following properties of the blocked material were being controlled: mass loss of the sample, foaming coefficient, density. Determination of these parameters was carried out on the samples of the correct form with dimensions of $100 \times 100 \times 35 \mathrm{~mm}^{3}$ using the following methods:

Mass loss is calculated by the formula:

$$
W=\left(m-m_{1}\right) \cdot 100 / m_{1},
$$

where $W-$ mass loss, $\% ; m-$ mass of the sample before foaming, $\mathrm{g} ; m_{1}-$ mass of the foamed sample, $\mathrm{g}$.

The foaming coefficient is calculated by the formula:

$$
K=V_{k} / V_{p}
$$

where $K$ - foaming coefficient; $V_{k}-$ volume of the sample before foaming, $\mathrm{g} ; V_{p}-$ volume of the foamed sample, $\mathrm{g}$.

Density of foamed materials is determined in accordance with GOST 17177-94 in the state of natural moisture. The samples are weighed using analytical scales with accuracy up to $0.1 \mathrm{~g}$, then their volume is calculated. Density of the sample in the state of natural moisture is calculated by the formula:

$$
\rho=M_{v} / V \cdot(1+0.01 \cdot W)
$$

where $\rho-$ sample density, $\mathrm{kg} / \mathrm{m}^{3} ; M_{v}-$ sample mass in the state of natural moisture, $\mathrm{kg} ; V$ - sample volume, $\mathrm{m}^{3} ; W-$ sample moisture, \% [8].

\section{Results and discussion}

Moisture which is a part of liquid glass, is divided into the following types:

- free (it can be removed firstly with a high rate; contained in cavities, pores and on the surface),

- adsorption (firmly held by the forces of intermolecular interaction on the surface of pores in the form of a monolayer or several layers; its removal is connected with its transformation into vapour inside the material);

- connected (the hardest one to remove only by evaporation at temperatures above $100-120^{\circ} \mathrm{C}$, has the greatest binding energy with the material) [9].

If the foaming process of the liquid glass is carried out in forms with closed volume, then one can get finished products with the given shape and dimensions. During implementation of such a technology, there arise the problems associated with the high relative moisture of liquid glass (50-60 wt. \%), 
which leads to formation of extremely inhomogeneous products with large-pore structure in the process of heating and removal of this water. In order to eliminate these undesirable phenomena, it is necessary to remove practically all free moisture (removed at temperature from 60 to $105^{\circ} \mathrm{C}$ ) from the liquid glass and leave firmly bound moisture, removed at temperature above $110^{\circ} \mathrm{C}$, which takes part in the foaming.

The conducted researches allow finding the optimum conditions of liquid glass composition foaming with usage of microwave irradiation to achieve the effective removal of all types of moisture.

At the beginning, the research of the block production process was carried out at power of $500 \mathrm{~W}$ without rotation of the sample in the medium of rarefied air (pressure of the process at launch of the equipment was about $10 \mathrm{kPa}$; this index was achieved by air pumping out from the equipment chamber). Air rarefaction was carried out in order to exclude impact of the condensed moisture in the chamber on duration of the process and the properties of the samples studied. To analyze whether it is possible to foam only due to evaporated structurally bound water, without additional gas formation, it is necessary that the binder does not contain a gas-generating agent.

At launch of the equipment, a sharp drop in the temperature was observed in the microwave chamber, i.e., the beginning of porosity and simultaneous condensation of moisture on the surface of the resulting sample was observed. The rarefied environment inside the equipment allowed eliminating this defect and provoking the intensive increase in the process temperature. A sharp jump in the temperature did not occur, its gradual growth was observed throughout the process and stopped only at the 10th min, as curve 1 presents, shown in Fig. 1.

Despite the achieved high process temperature at a low pressure index (no more than $10 \mathrm{kPa}$ - above $100^{\circ} \mathrm{C}$, no intense foaming was observed, as indicated by the low rate of the foaming coefficient -1.42 .

As a result, after the process was over, mass of the sample was $26.7 \%$, density was $0.48 \mathrm{~g} / \mathrm{cm}^{3}$. This material density index is high for the heat-insulating material, so it is advisable to use the gas-generating agent. Decrease in mass of the sample is determined by the mechanism of moisture removal with the help of vacuum, which leads to the higher rate of mass transfer

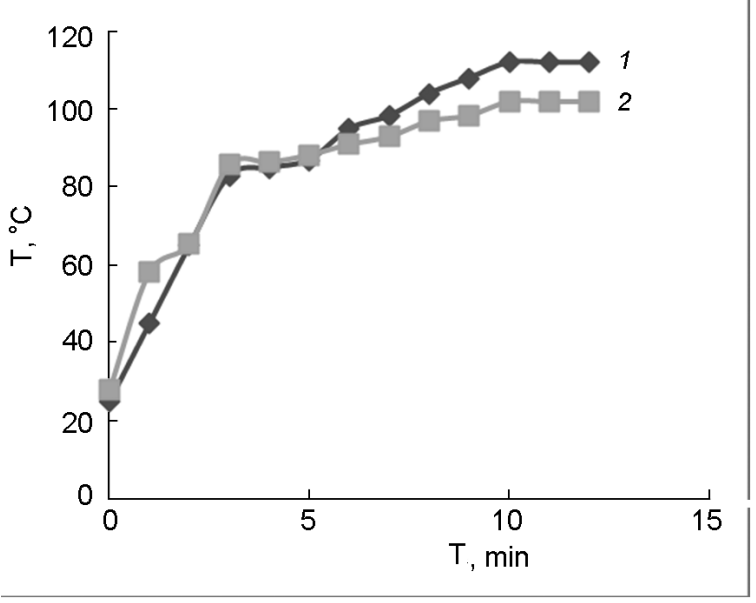

Fig. 1. Dependences of the process temperature on its duration with different quantities of gas-generating agent, power $500 \mathrm{~W}$ : 1 without gas-generating agent; $2-10$ wt. pts. of gas-generating agent.

without the stage of evaporation. In fact, water from the liquid glass composition was removed in the form of a liquid phase (fog), and foaming of the composition occurred only at the expense of small amount of constitutional water.

Further research was carried out using the gas-generating agent under conditions similar to those of the previous research (Fig. 1, curve 2). As a gas-forming agent, a concentrated aqueous solution of hydrogen peroxide was used, under decomposition of which oxygen is released, and the gas is absolutely non-toxic and non-flammable. The presence of the connecting gas-forming agent contributes to a more intense generation of pores (as seen from the photo structure of the material depicted in Fig. 2) and as a result of the lower material density. As it can be seen from the figure, the free moisture contained in the liquid glass composition was practically completely removed at the $3 \mathrm{rd}$ min and there was intense foaming of the binder due to bound water and gas evolution as a result of the gas formation reaction (temperature increase). Then intensity of the process falls, the temperature rises slowly, as the temperature gradually increases from 95 to $108^{\circ} \mathrm{C}$ and drying of the material begins. Apparently, in the low pressure medium, the foaming process runs smoothly, without sharp jumps of the temperature.

Mass loss of the sample was $29.2 \%$, the foaming coefficient was 2.46; density $0,42 \mathrm{~g} / \mathrm{cm}^{3}$. Comparing with the previous research, application of the gas-generating agent made it possible only to achieve in- 


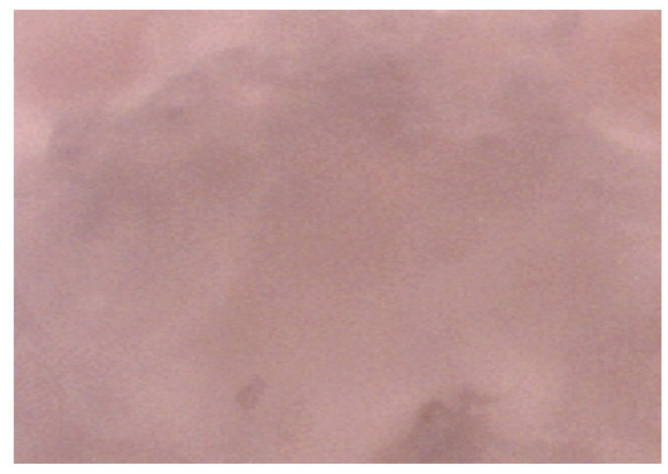

a)

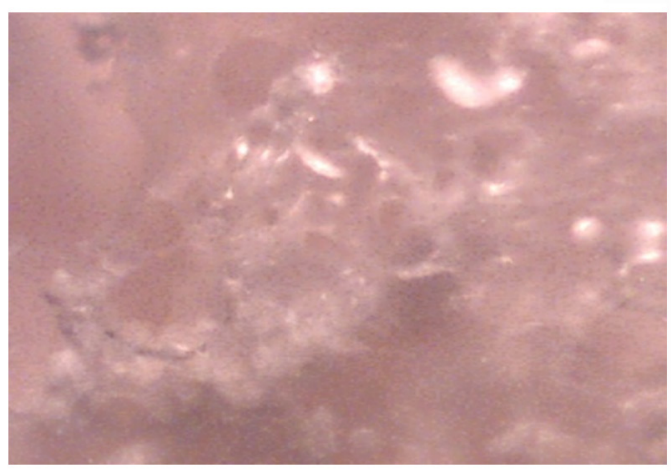

b)

Fig. 2. The structure of the block heat-insulating materials: a) - without a gas-forming agent, b) -10 parts by weight of a gas-forming agent.

crease in the foaming coefficient and slight decrease in material density, but it was not enough to use the obtained material as heat insulation. In addition, the surface of the finished foamed sample had inhomogeneous, "wavy" appearance due to influence of condensed moisture vapour on the sample separate parts. Along with this, there was no rotation of the sample during the foaming process, which led to uneven heating of the layer of the liquid glass composition and granular filler.

Based on the results obtained, the next research was carried out with rotation of the sample (Fig. 3) in order to achieve smooth heating and pore formation throughout the volume.

As it can be seen from the figure, creating the rarefied medium in the chamber by means of air pumping through the vacuum path causes even growth and low temperature of the sample and smooth progress in the process of block foaming. The constant temperature inside the camera affects the 10 th min and does not change further. For the sample obtained, mass loss was $26.6 \%$, the foaming coefficient was 2.88; density is $0.28 \mathrm{~g} / \mathrm{cm}^{3}$. However, too intense foaming of the binder and low pressure inside the chamber lead to appearance of a large number of "craters" on the surface of the sample and large through pores in the macrostructure. To eliminate this effect, the next experiment was conducted at higher power of $650 \mathrm{~W}$ (Fig. 3). The starting pressure was $9.5 \mathrm{kPa}$ and was maintained at this level during the whole process with the help of constant pumping of air through the vacuum path.

As it can be seen from Fig. 4 (curve 1), a sharp jump of the temperature at the 3rd

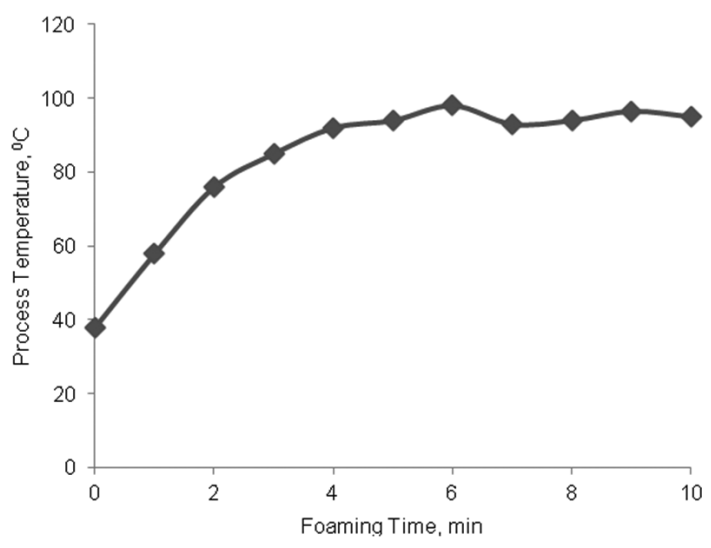

Fig. 3. Dependence of process temperature on foaming duration with rotation of the sample at power of $500 \mathrm{~W}$.

minute of the process up to $80.7^{\circ} \mathrm{C}$ is determined by beginning of evaporation of free and constitutional water from the structure of the liquid glass composition. Since the liquid glass composition contains large amount of liquid phase, the resulting vapour induced decrease in the process temperature to $58.9^{\circ} \mathrm{C}$ (at the 6 th $\min$ ). Further, at the 7 th mine, slight increase in the temperature to $75^{\circ} \mathrm{C}$ indicated the most intense process of evaporation of bound water, then the drying process began, as the temperature gradually decreased and reached a constant value. Mass loss of the sample was $59 \%$, the foaming coefficient was 2.27; density $-0.24 \mathrm{~g} / \mathrm{cm}^{3}$. Since the foaming coefficient in this mode was lower than in the previous research, which was carried out at the lower power, and mass loss, on the contrary, increased significantly, it can be concluded that at $650 \mathrm{~W}$ 


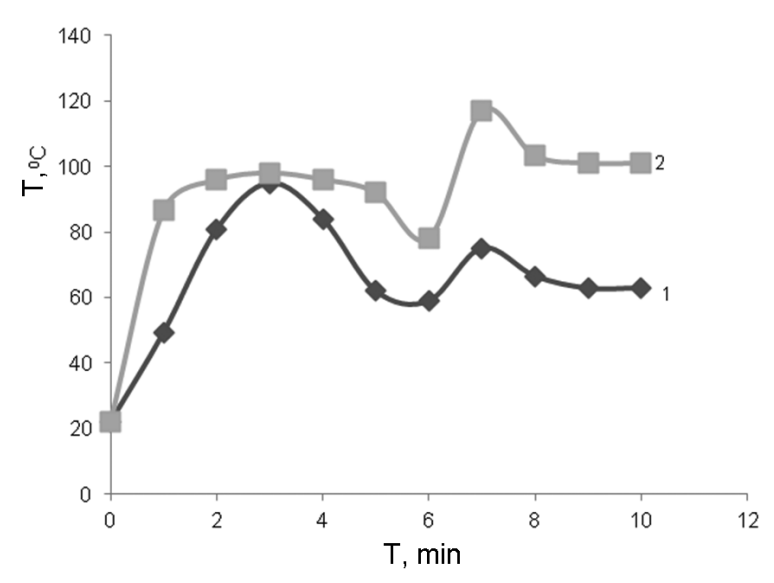

Fig. 4. Dependence of process temperature on process duration at $650 \mathrm{~W}: 1$ - in the medium of rarefied air; 2 - at atmospheric pressure.

and in the vacuum medium it was impractical to obtain the material, since in its structure there were competing processes of mass transfer of water with its evaporation. Therefore, the next research was conducted at atmospheric pressure.

Launch pressure of the process was $100 \mathrm{kPa}$, and maintained further at $81 \mathrm{kPa}$ (closer to atmospheric), with power of $650 \mathrm{~W}$. At the 6 th min of the process there was decrease in the temperature to $72^{\circ} \mathrm{C}$ (Fig. 4, curve 2), since evaporation of free water and a part of bound one begun, and vapour of moisture caused decrease in the temperature condensing on the walls of the equipment and on the surface of the sample. The seventh minute of the process was marked by sharp increase in temperature to $117^{\circ} \mathrm{C}$, and, consequently, the most intense foaming process. The mass loss of the sample was $61 \%$, the foaming coefficient was 2.5; density $-0.23 \mathrm{~g} / \mathrm{cm}^{3}$.

Based on the data given in Fig. 4, we can make a general conclusion for the process of foaming of the blocks at power of $650 \mathrm{~W}$ : regardless of the process pressure, foaming is characterized by two distinct periods the period of intense foaming of granules and the binder, and the period of drying of the sample. Both the first and the second periods are characterized, at first, by gradual increase in the temperature (removal of free water) and its fall (all free moisture is removed), then again increase in the temperature (intensive process of vaporization of the bound water) and its gradual decrease and reaching the constant level.

\section{Conclusions}

While conducting these researches, determining the optimum conditions for foaming of the liquid glass composition with usage of microwave irradiation has been made to achieve the effective removal of all types of moisture. Based on the experiments carried out, the following conditions are optimal for obtaining the block heat-insulating materials on the basis of the liquid glass granules and the binder, and achieving the high foaming coefficient and low density ratio: power of the equipment is $650 \mathrm{~W}$, the sample rotation, the starting pressure is $100 \mathrm{kPa}$, pressure during the process is $81 \mathrm{kPa}$. The obtained samples are characterized by the high rates of fluctuation, the high ductility, which makes it possible to use them as heat-insulating materials.

Acknowledgement to the employes of the SSI "Institute for Single Crystals" of the NASU V.A.Chebanov and N.O.Pinchukova for technical assistance in conducting the research.

\section{References}

1. http://www.ref.by/refs/1/35861/1.html.

2. V.A.Lotov, V.A.Kutugin, V.V.Revenko, Glass and Ceram., 11, 19 (2009).

3. V.A.Lotov, Constr. Mater., 11, 8 (2004).

4. U.S. Patent 1803693 (2007).

5. U.S. Patent 9018139 (2015).

6. U.S. Patent 6818055 (2004).

7. U.S. Patent 20130029885 (2013).

8. GOST 17177-94 (2001).

9. N.I.Malyavskij, Rus.Chem. J., 4, 39 (2003). 